\title{
ANÁLISE DISCURSIVA DO LIVRO DIDÁTICO DE INGLÊS DA 11ª CLASSE USADO EM ESCOLAS PÚBLICAS E PRIVADAS DE ANGOLA
}

\author{
Discursive Analysis of the \\ $11^{\text {th }}$ Grade English Textbook Used in \\ Análisis discursivo del libro de texto \\ Angolan Public and Private Schools \\ de Inglés de $11^{\text {a }}$ clase utilizado en \\ escuelas públicas y privadas de Angola
}

\author{
Dinis Fernando da Costa* \\ Instituto Superior Politécnico Gregório Semedo, \\ Departamento de Ciências Sociais, Namibe, Angola
}

\begin{abstract}
Resumo: Considerando a importância dos livros didáticos na sala de aula, em contexto de ensino da língua inglesa, este artigo aborda, por um lado, a eficácia desses materiais para o ensino-aprendizagem em termos da relação existente entre a linguagem verbal e iconográfica (imagens); por outro, explora a representação étnica e sociocultural das personagens inerentes ao referido manual e seus efeitos para o ensinoaprendizagem. $\mathrm{O}$ estudo emprega a análise qualitativa discursiva e faz uma análise do manual de inglês da $11^{a}$ Classe, usado nas escolas de Angola. Recorrendo à teoria de Análise Crítica de Discurso (ACD), os resultados apontam que a linguagem verbal e as imagens constantes no manual nem sempre se relacionam ou complementam. De igual modo, a representação étnica assimétrica incentiva estereótipos como preconceitos sociais, étnicos e raciais nos alunos, fragilizando assim a própria identidade desses alunos e o conceito de pluralidade social que, no todo, pode afetar o ensino-aprendizagem.
\end{abstract}

Palavras-chave: Livro didático. Análise discursiva. ACD. Ideologia. Inglês.

\begin{abstract}
Considering the importance of textbooks for teaching English in the classroom, this paper firstly explores the effectiveness of such materials for the teaching-learning process in the relation between verbal and iconographic language; secondly it also explores the ethnic and sociocultural representation of the characters presented in the texbook and its effects on teaching and learning. This study investigates the $11^{\text {th }}$ grade English textbook used in Angolan schools, employing a qualitative and discursive analysis with use of the Critical Discourse Analysis (CDA) as theoretical and methodological foundation. The results show that verbal and visual approaches in the textbook do not always relate to or complement each other. Similarly, the asymmetrical ethnic representation encourages stereotypical behaviors of all kind, including social, ethnic and even racial prejudices on students, weakening their own identity as well as the concept of cultural plurality that can affect the teaching and learning in whole.
\end{abstract}

Keywords: Textbook. Discursive analysis. CDA. Ideology. English.

Resumen: Teniendo em cuenta la importancia de los libros de texto em las clases, em contexto de enseñanza de lengua inglesa, este artículo se direcciona, de un lado, para la eficacia de estos materiales para la enseñanza-aprendizaje em términos de la relación existente entre lenguaje verbal e iconográfica (imágenes); de otro, explora la representación étnica y sociocultural de los personajes inherentes al dicho manual y sus efectos para la enseñanza-aprendizaje. El estudio emplea el análisis cualitativo discursivo y hace un análisis del manual de ingles de la $11^{\text {a }}$ Clase utilizado en las escuelas de Angola. Basados en la

\footnotetext{
* PhD em Linguística pela University of Western Cape, África do Sul. Professor de Lingua Inglesa como língua estrangeira. ORCID: https://orcid.org/0000-0002-6738-6337. E-mail: dinis.costa@igs.ed.ao / ddacosta212@gmail.com.
} 
teoría del Análisis Crítico del Discurso (ACD), los resultados apuntan que el lenguaje verbal e las imágenes del manual ni siempre se relacionan o complementan. De igual manera, la representación étnica asimétrica incentiva estereotipos, como preconceptos sociales, étnicos y raciales en los alumnos, debilitando así la propia identidad de eses alumnos y el concepto de pluralidad social que, en conjunto, pueden afectar la enseñanza-aprendizaje.

Palabras clave: Libro de texto. Análisis discursivo. ACD. Ideología. Ingles.

\section{INTRODUÇÃO}

No Século XXI, com a globalização, intensificaram-se em toda parte do mundo os esforços no ensino e na aprendizagem da língua inglesa como uma língua estrangeira, não estando Angola alheia a esta realidade. Num discurso recente, João Lourenço, o atual presidente de Angola, apontou a necessidade e o interesse de Angola aderir à Commonwealth, organização constituída na sua maioria por estados colonizados pelo antigo Império Britânico, argumentando que, a "exemplo do que se passa com Moçambique, que está encravado entre países anglófonos e acabou por aderir já à Commonwealth, também Angola está cercada, não por países lusófonos, mas por países francófonos e anglófonos" (JORNAL DE NEGÓCIOS PT, 06/06/2018).

Alinhado ao plano de João Lourenço, o Ministério de Educação de Angola, em 2001, embarcou num projeto ambicioso com o intuito de reformar o sistema de educação. Denominada $2^{a}$ Reforma do Sistema de Educação, aprovada através da Lei de Base do Sistema de Educação, o projeto, cuja implementação ocorreu a partir de 2004, tinha como objetivos, dentre vários, "a expansão da rede escolar, o reforço da eficácia do sistema de educação e a equidade do sistema de educação" (GOVERNO DE ANGOLA, 2014, p. 3), e principalmente alavancar o ensino de qualidade, visto que:

\footnotetext{
Após a Independência, Angola defrontou-se com a existência de um sistema educativo totalmente decalcado do modelo português, com infraestruturas escolares genericamente localizadas nos centros urbanos, com fraca acessibilidade e equidade relativamente às populações autóctones, de que resultavam em taxas de escolarização muito reduzidas e um elevado índice de analfabetismo que rondava os $85 \%$ da população (GOVERNO DE ANGOLA, 2014, p. 3).
}

Nesta reforma, a língua inglesa tem lugar de destaque, tendo sido classificada geopolítica, econômica e socialmente preponderante para o desenvolvimento do País, por: (a) ser uma língua com carácter internacional comparando-a a qualquer outra; (b) ser uma língua oficial da ONU e veículo de acesso à investigação e informação; (c) Angola ser um dos países membros do organismo de desenvolvimento dos países da África Austral (SADC), cuja língua de trabalho é o inglês; (d) Angola geograficamente ser vizinha de países anglófonos como Zâmbia, Namíbia, Zimbabué, África do Sul (PROGRAMA DE LÍNGUA INGLESA, 2013). Além disso, segundo Barbosa (2013), a língua inglesa é objeto de desejo social, sendo que ela "figura como a mais importante devido a seu vasto uso e abrangência” (PILATTI; SANTOS, 2008, p. 2). 
A atitude de investimento na Educação, por parte do Governo de Angola, acarreta dimensões imperativas atendendo à necessidade de competir, educacionalmente, com outras nações, tanto da região subsariana como de outras regiões de África e de outras partes do mundo, que partilham a escala em termos de desenvolvimento socioecônomico, político e não só.

Contudo, é de notar que, sete anos após as fases de implementação da Reforma, a última das quais em 2012, "que consistia na avaliação e correção dos materiais pedagógicos e dos dispositivos da Reforma Educativa" (GOVERNO DE ANGOLA, 2014, p. 3-4), vê-se que o esforço implementado parece infrutífero, visto que, no que tange a esta disciplina (em estudo), ainda nos deparamos com materiais didáticos concebidos à luz de modelos eurocêntricos, com textos inadequadamente enquadrados sociocultural, étnica, econômica e politicamente à realidade do público-alvo.

Este artigo apresenta duas vertentes. A primeira tem como objetivo analisar, discursivamente, a relação existente entre a linguagem verbal e a não-verbal (imagens), para averiguar até que ponto a mesma relação impacta negativa ou positivamente no processo de ensino-aprendizagem. Já a segunda explora os aspetos de representatividade etnicocultural e social e seu impacto no ensino-aprendizagem.

\section{FOCO DO ESTUDO}

De uma forma geral e sucinta, o trabalho tenta responder às seguintes questões:

a) Como a linguagem verbal e a iconográfica se integram numa realização ou composição semiótica única?

b) Em que medida as imagens utilizadas no livro didático em estudo refletem a realidade sociocultural e multiétnica de Angola?

\section{PRESSUPOSTOS TEÓRICOS}

Convém-nos realçar que o estudo é sustentado na Análise Crítica do Discurso (ACD) de Van Dijk (1995, 2006) e Fairclough (2008, 2012), principalmente, e em outros acadêmicos de reconhecido mérito como Machin e Mayr (2012), Kumaravadivelu (2016), Sousa (2009), Anjos (2017) etc. Com efeito, o uso deste framework ajusta-se devidamente ao que objetivamos, considerando que "em princípio ACD é tida como tipo de investigação analítica discursiva que estuda, principalmente, o modo como o abuso de poder, a dominação e a desigualdade são representados, reproduzidos e combatidos, por textos no contexto social e político" (VAN DIJK, 1995, p.113). É notável que a ideologia de sub-representação visível no livro didático em estudo, onde um grupo parece estar em eminência étnica e social em detrimento de um outro, é um exemplo de abuso de poder e um sinal de dominação, práticas essas que a ACD investiga. A partir desta abordagem, percebe-se também que o fato de a ACD conceber a linguagem como prática social, levando em consideração o contexto em que a linguagem é usada (FAIRCLOUGH, 2008), torna relevante a escolha desta teoria para este estudo. Devemos, contudo, enfatizar que a ACD, segundo Wodak e Meyer (2008), é multifacetada, e que deriva de diferentes disciplinas que se orientam por vários corpora e metodologias. 
A escolha, no entanto, deve-se também ao fato de a "ACD ter uma perspetiva teórica e metodológica sobre a língua, ou seja, sobre a semiose que inclui a linguagem visual, corporal, sons, filmes, etc." (FAIRCLOUGH, 2012, p. 307-308) e fazer uma análise das relações dialéticas entre semioses e outros elementos das práticas sociais. A dialética, neste contexto, explica a interação entre os vários sinais, verbais e não-verbais, que se ajustam a estudos com esse caráter de duas vertentes analíticas pertinentes.

A ACD surgiu como o campo novo de transdisciplinaridade de estudo em meados de 1960, por meio do trabalho de Fairclough (HANRAHAN, 2010) e desenvolveu-se nos princípios dos anos 90, após um simpósio em Amesterdão, em 1991, que juntou vários acadêmicos de notabilidade nesta disciplina, entre os quais Teun van Dijk, Norman Fairclough, Gunther Kress, Theo van Leeuwen e Ruth Wodak (WODAK; MEYER, 2008) e, desde então, esta disciplina se tem preocupado particularmente "com as mudanças radicais na vida social contemporânea, no papel que a semiose tem dentro dos processos de mudança e nas relações entre semiose e outros elementos sociais dentro da rede de prática" (FAIRCLOUGH, 2012, p.307-308).

A ACD foca em "causas subjacentes de ideologias que ajudam na reprodução de/ ou resistência contra a dominação ou inequalidades" (VAN DIJK, 1995, p.18). No entanto, tem "como objeto de estudo estruturas discursivas legitimadas ou representadas e estratégias de dominação e resistência em relações sociais de classe, gênero, etnicidade, raça, orientação sexual, língua, religião, idade, nacionalidade, etc.” (VAN DIJK, 1995, p.18).

O conceito de ideologia é pertinente para este estudo, visto que a produção dos textos em estudo é deliberadamente orientada. Do contrário, pareceria inexplicável, a julgar pelo histórico dessa gigantesca editora - Porto Editora - fundada em 1944, com uma vasta experiência na produção de manuais escolares, dicionários e outros produtos ligados à educação e internet em diversos países, assumir uma postura de produção de manuais cheios de estereótipos explícitos, ignorando a informação do contexto social, cultural, político e econômico do público-alvo.

Nesta ordem de ideias, Wodak and Meyer (2008) definem ideologia como um conjunto ou sistema de crenças ou valores. Já Awan argumenta que "pessoas adquirem, expressam e reproduzem suas ideologias, de um modo geral, por meio de discurso escrito e oral" (2008, p. 115). Assim sendo, as "pessoas são representadas de acordo com o posicionamento de ideologias dominantes que servem para dar forma e controlar como indivíduos entendem outros e suas próprias identidades" (AWAN, 2008, p. 12). De todo modo, Wodak e Meyer (2008) ressaltam ainda que as organizações que lutam para obter poder vão tentar influenciar a ideologia da sociedade em trazê-la próxima de suas crenças. Corroboramos plenamente o pensamento destes dois acadêmicos. É evidente que muitas editoras do mundo ocidental, com ideologias europeizadas, tentam, a todo custo, desenvolver textos de modo a servir a seus interesses neocolonialistas de caráter ideológico e econômico (visando o lucro), principalmente. Assim sendo, muitas delas recorrem a estudos superficiais das culturas a quem os materiais didáticos deveriam beneficiar. A esse respeito, Barbosa (2013) destaca que o material didático no ensino de línguas tornou-se comum, fomentando lucros vultosos para o mercado editorial, mas nem sempre esses livros são analisados criticamente, neste caso considerando as modalidades verbal e não-verbal. 
Retomando a discussão sobre a ACD, uma de suas grandes virtudes, segundo van Dijk (1995), é o fato de que, entre os vários objetivos (descritivo, explicativo e prático), esta tenta desvendar ou revelar o que é implícito, escondido ou algo que não está imediatamente óbvio. Desta forma, a ACD "tenta formular ou suster uma perspetiva total de solidariedade com o grupo dominado, por exemplo em apresentar propostas que contrariam o poder e as ideologias em práticas de desafio e resistência" (VAN DIJK, 1995, p. 18). Observemos que Lakoff e Johnson (1999, citados por Wodak e Meyer (2008), demonstram uma questão digna de realce: “ [...] não é aquele tipo de ideologia superficial da cultura que interessa à $\mathrm{ACD}$, mas sim as crenças do dia-a-dia do tipo latente e escondidas, que geralmente aparecem disfarçadas como analogias e metáforas conceituais". Este argumento explica a composição das imagens em termos de representatividade assimétrica dada aos grupos étnicos em questão no livro didático, onde a ideologia dominante é sintetizada como 'brancura', que, segundo Wodak e Meyer (2008), surge como neutra, ou melhor, normal dentro de uma sociedade.

\section{ASPETOS METODOLÓGICOS}

Importa, pois, sublinhar que fazemos uma análise qualitativa discursiva ao livro didático da $11^{\text {a }}$ Classe de inglês usado tanto nas escolas do setor público quanto nas do privado, em Angola. O livro contém 141 personagens de unidade de leitura incluindo banda desenhada. Destes, 123 retratam imagens de personagens de raça ou etnia branca, 13 de preta e 5 sem caraterização, no entanto denominadas 'outras'.

Deste modo, fazemos uma análise de sete unidades de leitura (imagens), em função dos seguintes subtemas: relação linguagem verbal e visual e representação étnica. Neste âmbito, três para o primeiro caso, e uma análise global de todo o livro, para o segundo caso. As unidades de leitura foram cuidadosamente selecionadas após uma pré-análise em termos da contribuição de cada uma para os temas identificados para análise discursiva. Em poucas palavras, a análise foca, de um modo geral, em aspetos discursivos e imagísticos dos textos didáticos (BARBOSA, 2013), portanto as imagens que achamos estar distante desta realidade (por exemplo, as que se referem à infraestrutura) foram excluídas, embora acreditemos serem relevantes para aqueles que queiram explorar esses aspetos.

No que se refere à decisão de classificar uma unidade de leitura, devemos admitir que foi um desafio para chegar a este pressuposto; questões como o que na realidade constitui uma unidade de leitura ou não foram alguns dos desafios enfrentados. No caso da imagem (veja Figura 4), por exemplo, que retrata the family, deveria ser considerada como uma unidade ou várias atendendo ao fato de cada figura iconográfica ser independente, em termos interpretativos, no contexto de família? Contudo, pareceu-nos procedente contá-las separadamente, mas, em casos em que se trata de banda desenhada (veja Figura 3), achou-se melhor considerá-la uma unidade, visto que trata da vida de um único personagem.

Para terminar esta seção, vale a pena realçar que os termos 'raça' e 'étnico' são usados simultaneamente na pesquisa com o mesmo significado, cor da pele, mas somente por razões pertinentes à estatística de representatividade das personagens não é um caso político; o estudo por simples verdade é colorblind. 


\section{RELAÇÃO ENTRE LINGUAGEM VERBAL E VISUAL}

A começar com a imagem da Figura 1, que reflete, de uma ou de outra forma, a realidade das escolas públicas e, em alguns casos, privadas de Angola, em termos de número de estudantes na sala de aula, deixa dúvidas se se trata mesmo de um evento de ensino-aprendizagem (aula) ou não. Vemos, por exemplo, um menino na segunda fila, à direita, com um embrulho, e os demais alunos estão desprovidos (sem nada às mãos), atentos como se estivessem a ouvir um palestrante ou assistir a um vídeo. O fato de os alunos estarem de mãos vazias, sem cadernos, livros, nem mesmo lápis ou canetas, dános evidência de que o evento não tem qualquer relação com uma aula normal. Mesmo assim, o(a) autor(a), sob o título writing, orienta a seguinte atividade: 'Write a short composition about your partner's daily routine' / [Faça uma breve redação acerca da rotina diária de seu parceiro(a)/companheiro(a)]. A instrução, por se tratar de um evento na sala de aula e não em casa, sugere uma atividade supervisionada pelo professor ou orientador. Contudo, várias questões surgem sobre a contribuição dessa imagem ao processo de ensino-aprendizagem: por exemplo, quem é parceiro de quem entre estudantes? Como os alunos vão escrever se eles, como se vê, não dispõem de materiais necessários para uma redação possível?

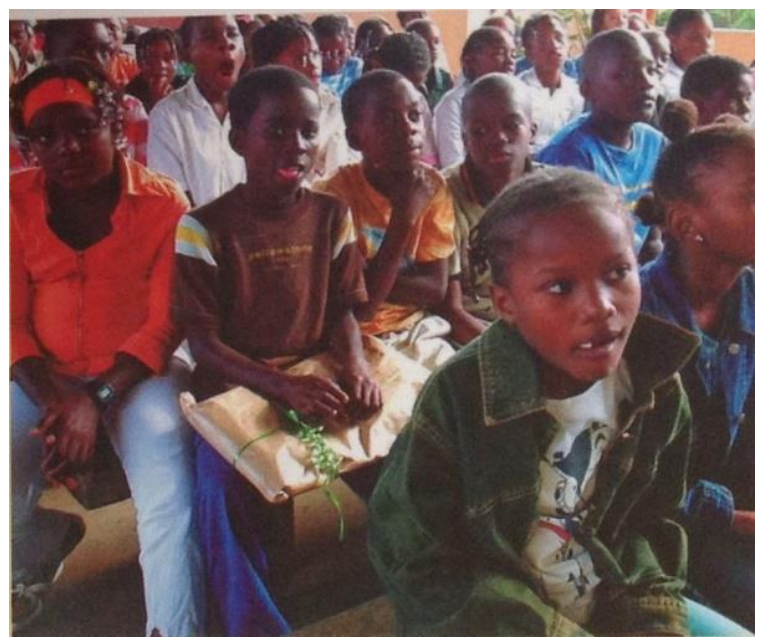

Figura 1 - Suposta sala de aula na escola pública

Fonte: Manual de Inglês 11ㅡㅡㄹ Classe 2014.

Com efeito, para que houvesse claridade na compreensão entre a linguagem verbal e a iconográfica, neste contexto, admitimos a sugestão mediante a qual os alunos estivessem sentados nas carteiras, em pares, preferencialmente, ou então o exercício escrito tivesse duas vertentes:

A instrução orientasse que os alunos tivessem uma conversa com seus colegas (parceiros), à escolha deles ou do professor.

Que após a mesma se escrevesse a redação. 
Mesmo assim, para facilitar a interpretação, a imagem teria de sugerir um ambiente adequado à sala de aula e não o que se pode ver (uma espécie de evento de entrega de prêmios ou presentes, sem, necessariamente, sugerir algo relacionado ao contrário).

Justificando este critério de simetria entre a linguagem verbal e não-verbal, na visão de Souza (2009), é importante tornar evidente a relação entre imagem e texto a fim de mostrar ao aluno que, antes de ler o texto, pode inferir várias coisas a respeito dele, apenas ao olhar atentamente para a imagem. Com este pensamento, Souza (2009) claramente salienta a importância da linguagem verbal e da não-verbal quando ambas são utilizadas efetivamente com objetivo comum. Porém, isto só se concretiza em situações onde há uma clara relação entre a imagem em si e o texto. Essa simbiose que existe entre "a linguagem verbal e as outras modalidades semióticas tem a função de reforçar significados, dizendo a mesma coisa de modo diferente, desempenhar papéis complementares na construção de significados ou promover uma ordenação dos siginificados"(TILIO, 2006, p. 73 e 121). Quando o contrário ocorre, cria dificuldades aos alunos em perceber as instruções das atividades, como vimos na Figura 1.

Entretanto, podemos admitir que essa imagem tenha sido inserida no livro sem uma análise crítica de sua contribuição para o processo de ensino-aprendizagem do aluno e, portanto, inefetiva em termos de contribuição para o referido processo. Neste sentido, parece-nos claro que, por um lado, os materiais didáticos produzidos para o consumo global, apoiando-nos nas palavras de Carmagnani (1999), têm a tendência de trazer uma imagem de qualidade que nem sempre representa um mundo real; por outro, o investimento real não está na qualidade pedagógica, mas no potencial mercadológico.

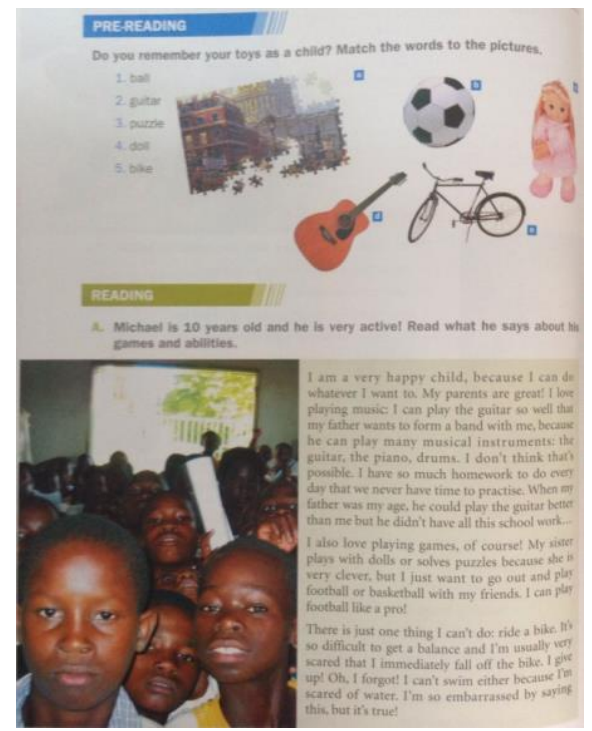

\section{Figura 2 - Childhood}

Fonte: Manual de Inglês 11ํㅡㄹ Classe (2014).

A Figura 2, com o título principal 'childhood' (infância), instrui o aluno a fazer a leitura do texto: 'Michael is 10 years old and he's very active! Read what he says about his games and abilities' I [O Michael tem 10 anos de idade e é uma pessoa muito ativa! Lê o que ele diz acerca das suas habilidades e jogos], no entanto não ajuda muito na compreensão da instrução, por várias razões: 
A imagem em si não é clara a identificar quem é o Michael no coletivo, tornandoo quase invisível, embora nos dê uma indicação de que seja a pessoa mais frontal na imagem (com camisa às riscas azul), ou ainda, talvez, seja a pessoa à esquerda que também se destaca na imagem;

O texto centra-se na descrição da vida do Michael e sua família; seria conveniente que esta imagem fosse de índole individual (retratando particularmente o Michael ou Michael e sua família), não o coletivo (veja também Figura 5 no Apêndice) de pessoas alheias como mostra;

Apesar de a linguagem verbal sugerir que Michael é ativo em praticar desporto e tocar vários instrumentos, a imagem "fala" o contrário, os instrumentos musicais em referência estão de um lado (parte superior da imagem de Michael) e Michael noutra (parte inferior da imagem), como se não houvesse uma afinidade direta entre Michael e tais instrumentos, assim criando uma distância entre ambos. Presumivelmente, se Michael fosse identificado praticando ambas as atividades em outras figuras ou pelo menos uma das atividades mencionadas, daria outra dinâmica à interpretação, e também ao ensinoaprendizagem. No entanto, a disposição de imagens teria de ser: Michael vs. Imagens de Instrumentos Musicais e não Instrumentos Musicais vs. Michael. Nesse sentido, apesar de o ator ser personalizado, ou mesmo honorificado, ter um nome e ser tratado como tal, de nada serve (também por este não parecer feliz, como o texto diz). Por outro lado, a ideia de que ele toca vários instrumentos pode suscitar uma inverdade, visto que a disposição (imagem) visual não corrobora a linguagem textual. Ainda, quanto à representaçâo (composição) da imagem em termos de saliência, ou melhor, elementos que se destacam, os quais têm um valor simbólico (MACHIN; MAYR, 2012, p. 54), as cores exibidas têm uma tonalidade fraca e de pouca saliência, com um fundo quase a preto e branco. Se prestarmos atenção à composição ou à figura na parte superior, neste caso, a guitarra e a boneca, são realçadas (na perspetiva de uso de cores vivas) e não a figura em si que exibe o Michael, que seria a figura de destaque. Outra nota importante é o fato de que o grupo é homogeneizado, todos os meninos exibidos nesta composição são de raça (esse tema será abordado na próxima seção) preta e de classe baixa. Este tipo de representação parece ideológica e, portanto, sugere várias interpretações que podem comprometer a qualidade de ensino ao: (a) "reforçar o complexo de inferioridade por parte do grupo subalterno" (KUMARAVADIVELU, 2016, p. 78), neste sentido os meninos exibidos, e superioridade às demais raças excluídas; (b) criar distanciamento entre os vários grupos dentro da sociedade (o rico, o pobre, o de classe baixa, o da classe média, etc.). É importante aqui ressaltar que os discursos, sejam estes verbais ou nãoverbais, carregam ideologias e, assim sendo, "constituem parte de recursos que as pessoas utilizam para se relacionar - para se manterem separadas, para cooperar, competir, dominar e procurar mudar as maneiras em como se relacionam" ( FAIRCLOUGH, 2003, p. 124).

Contudo, é imperativo referir que uma descrição mais particular ao Michael como aquela dada ao menino 'branco' (Figura 3) tornaria a contextualização mais simples e simbólica. 


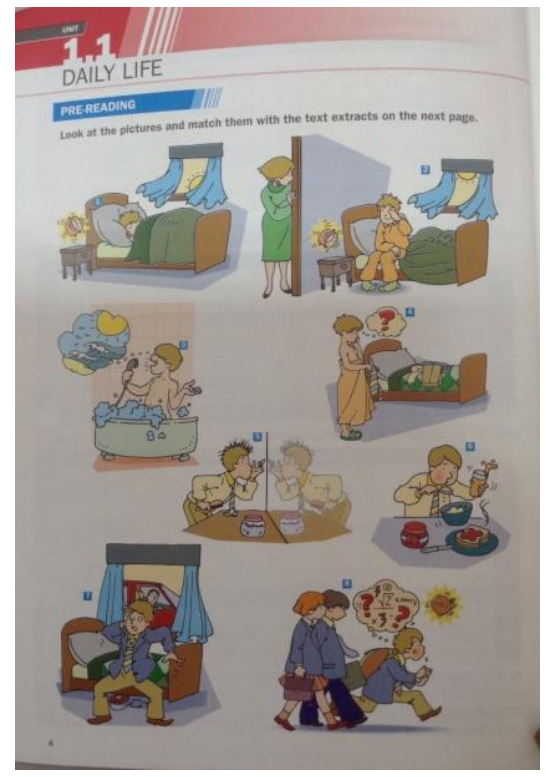

Figura 3 - Daily life

Fonte: Manual de Inglês $11^{\text {a }}$ Classe 2014.

Em última análise, a Figura 3, sob o título Daily life [A vida diária $]$, que refere um menino de raça branca, não se adequa de um modo geral ao comportamento representativo de uma família angolana em termos socioeconômicos e culturais. A julgar pela situação socioeconômica, poucos angolanos ostentam o lifestyle que esse menino exibe, que aparenta ser de classe média. Em muitas casas de famílias angolanas o banho é ainda em bacias ou baldes, usando uma caneca para despejar a água ao corpo, sem necessariamente incluir um chuveiro. As crianças não têm cereais, tosta, marmelada e sumo de laranja no café-da-manhã, sendo comum o pão com chá ou café, papa de milho e funge. As famílias são mais extensas; em muitos casos, abrangem, para além de filho(s), sobrinhos, primos, etc.

Sem dúvida, esta imagem personifica a criança de classe média angolana que representa uma percentagem insignificante da população, ou melhor, uma criança do mundo ocidental. Assim, a imagem não contribui significativamente para a aprendizagem do aluno, que precisará de outros recursos (por exemplo, a internet, que ainda é um objeto escasso), que o ajudarão a descobrir mais sobre a imagem em estudo. Perguntas como qual grupo étnico predomina em Angola, a que classe social a maioria de angolanos pertence, em que zonas (rural, semirrural ou urbana ou semiurbana) a maioria vive, de que se alimenta, ajudariam a definir uma melhor figura e criar uma personagem mais equilibrada à realidade do contexto socioeconômico, político, cultural e étnico de um menino típico angolano, que representa a maioria, não o contrário. Por exemplo, em Angola, o maior parte do agregado familiar é constituído por sete ou mais pessoas numa família, em média quatro a seis pessoas, perante uma pequena percentagem que regista apenas famílias monoparentais (CENSO, 2014). Esses indicadores apontam para uma realidade africana constituída por famílias extensas, compostas não exclusiva e necessariamente por filhos, mas por diversos membros de segundo, terceiro e posteriores graus de parentesco. 
Certamente, a representação do menino confirma, apoiando-nos nos argumentos de Block e Gray (2017), que os materiais de ensino de línguas estrangeiras estão repletos de ideologias que refletem particulares pontos de vista da sociedade e indivíduos dentro dela. Nesta perspetiva, visto que a "ideologia está contida não apenas nos conteúdos, mas também na forma de apresentação desse conteúdo e na forma da apresentação do livro, em seu aspeto físico, através de gravuras, diagramação etc.” (TILIO, 2006, p. 121, grifo nosso), pode-se inferir que o ato de representação exibido é ideológico não só com intenção de criar a hegemonia da classe poderosa mas também de continuar a manter a classe subserviente.

Em síntese, o fato de "os materiais didáticos representarem, se não a principal, uma das mais importantes fontes de conteúdo relevante que promovem a aprendizagem" (ORTIZ, 2012, p. 27), estes mesmos devem buscar:

\footnotetext{
Alinhar teoria e aplicação prática, levando em conta a cultura, os costumes locais, para que, dessa forma, o ensino e a aprendizagem se tornem mais significativos para alunos e professores, o que permitirá que o aluno se sinta parte desse processo (ANJOS, 2017, p. 17 18).
}

Esta reflexão de Anjos corrobora o plano do Governo angolano, que recomenda que as artes plásticas e o design de livros devem contribuir para a valorização e consolidação dos valores identários (DIÁRIO DA REPÚBLICA, 2011).

Desta feita, vale-nos destacar que os casos analisados, embora mais em termos qualitativos que quantitativos, apontam para uma única interpretação: de que há distanciamento entre a linguagem verbal e a iconográfica no livro didático, tornando o processo de ensino-aprendizagem complexo.

\section{REPRESENTAÇÃO ÉTNICA}

Angola é um país multicultural de grande heterogeneidade linguística, pelo que as diversas áreas socioculturais e linguísticas devem ser tidas em conta nas ações de promoção do livro e da leitura (DIÁRIO DA REPÚBLICA, 2011, p. 2978). Os dados do Gráfico 1 (abaixo) mostram que personagens brancas apresentam índices numéricos e percentualmente superiores comparado com outros grupos. Isto é, $87 \%$ de raça branca e 9\% não-branca. Por outro lado, a representação de membros de raça branca, em sua maioria, é feita individualmente e bem elaborada, enquanto membros de raça não-branca é feita de forma coletiva e menos elaborada, portanto menos valorizada. Para reforçar nosso argumento, evocamos Machin e Mayr (2012), os quais ressaltam que, quando a alguém é dado um tratamento individualizado, a tendência é criar sentimentos de aproximação e simpatia, enquanto à coletividade é dado um tratamento genérico (do grupo). Tal disposição num país onde, segundo Amaral (2018), somente 1\% da população é de etnia branca, $2 \%$ mestiços e o resto, neste caso, $97 \%$ não-branca, pode ser considerada como prática de ideologização de textos com preconceitos explicitamente organizados. Neste sentido, é, pois, importante salientar que ideologias "são crenças sociais de natureza geral e abstrata" (VAN DIJK, 2006, p.116), e entre as várias funções uma delas é "legitimar dominação e articular resistência" (VAN DIJK, 2006, p. 116). 


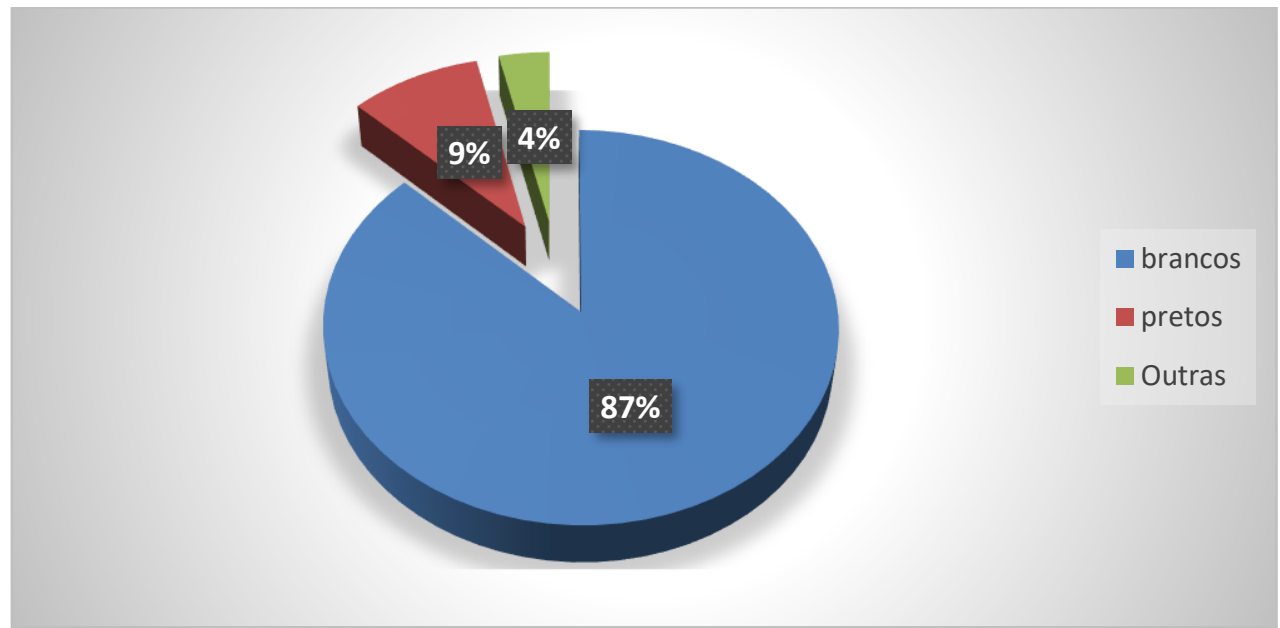

Gráfico 1 - Gráfico da representação étnica no manual de inglês

Fonte: Autor.

Não nos parece suscitar dúvidas o fato de que chega a "uma altura em que as ideologias são partilhadas vastamente ao ponto de parecerem parte de atitudes geralmente aceites numa sociedade, em termos de crenças ou opiniões óbvias e de bom senso" (VAN DIJK, 2006, p. 117). Notamos, claramente, quando o grupo de raça branca (a minoria) se destaca quando comparado com outros grupos, raça não-branca (a maioria em Angola) e mestiça. Aqui, a ideologia também funciona, na visão de van Dijk (2006, p. 117), “como a base de guias de comportamento social ditando como os vários grupos se articulam dentro da sociedade".

Neste material didático, o contexto de representação de grupos étnicos espelha exatamente este comportamento de imposição de normas etnicoculturais, sociais e econômicas aceitáveis dentro da sociedade através de ideologias eurocêntricas. Neste contexto, a injusta disparidade em representação de grupos étnicos "sustenta a falsa ideia" (SILVA, 2015, p. 7) de que o grupo étnico sub-representado é desprovido de certos dotes, o que o torna inferior em relação a outro grupo. Nesta vertente, concordamos com Rosemberg, Bazilli e Silva (2003), para quem a marca dos livros didáticos de estudo de línguas estrangeiras tem sido a perspetiva eurocêntrica.

Tomemos o exemplo da Figura 4, the Family Relationships (as Relações Familiares). Nesta imagem podemos indicar famílias representando distintos grupos étnicos de quase todos os lados do globo, oriundas da Ásia, do Centro ou Norte da Europa e/ou mesmo da América, inexplicavelmente ignorando quaisquer grupos étnicos africanos. Se sugerirmos que esses grupos étnicos aqui representados foram selecionados por pertencerem ao grupo New Englishes, estaremos a cometer um erro, visto que as estatísticas sugerem que o número de países de colônias britânicas na África parece irrisório. No mais, temos um país da África Austral de língua portuguesa, Moçambique, que aderiu à Commonwealth, logo, há muitos exemplos que poderiam se ajustar melhor a esta representação. Logo, tal justificativa seria de todo improcedente para nos convencermos dos estereótipos presentes neste arranjo. Em relação a este tipo de estrutura, Farias e Ferreira (2010, p. 2) fazem uma advertência argumentando que: 


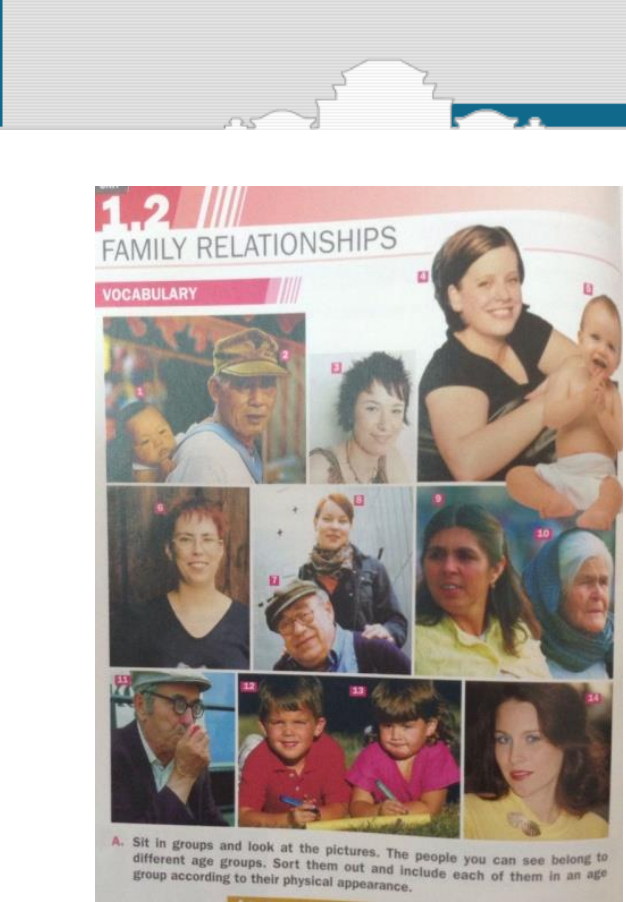

\section{Figura 4 - The Family Relationships}

Fonte: Manual de Inglês $11^{\text {a }}$ Classe 2014.

Os alunos, ao receberem informações sobre uma nova cultura, precisam ser consciencializados sobre a pluralidade cultural, a fim de que não desenvolvam uma visão limitada do assunto, criando assim a falsa impressão de superioridade de uma cultura em relação a outras culturas.

Sendo assim, esperava-se que, neste tipo de exposição, fosse oportuno ao livro:

a) Exibir uma abordagem ampla de vários grupos étnicos e culturais existentes em Angola, selecionados criticamente;

b) Buscar um exemplo da África (a África do Sul, por ser um país anglófono com vasta comunidade de raça branca, multicultural e multiétnico, serviria melhor como exemplo), os vários grupos étnicos vivendo harmoniosamente uns com os outros;

c) Explorar os exemplos de outras partes do mundo.

Para corroborar os pontos discutidos, Anjos (2017, p. 33) argumenta que:

Livros didáticos para ensino-aprendizagem de LE devem trazer em seu bojo questões locais, globais, numa perspetiva contemporânea, bem como devem retratar a diversidade de tais questões em níveis de igualdade, sem fazer generalizações ou menções que denotem inferioridade entre povos e nações.

Seguindo tal perspetiva de organização do material didático, "converge com os princípios da pedagogia crítica, pois ao politizar o ensino de língua, os professores estarão contribuindo para a formação de cidadãos, se não livres das relações de dominação, pelo menos conscientes" (ANJOS, 2017, p. 34). Quando isso não acontece, concebe-se o que o material nos oferece, sem opções de interpretação da representação exibida. Isto é, segundo Rosemberg e Piza (1996), a tendência ideológica dominante de embranquecimento para melhoria do status social. Em outras palavras, subentende-se que há o favorecimento de um determinado grupo social, publicizando um mundo ideal em 
detrimento do real, omitindo características, problemas e realidades de grupos sociais feitos minoritários (ANJOS, 2017).

A assimétrica representação, sem dúvida, descentraliza o plano ambicioso do Governo de Angola de Reforma Educativa, que tem "como base a identidade cultural [...] do aluno", com o fim de permitir que ele:

descubra e valorize os povos de diferentes comunidades, alargando os seus horizontes culturais e sociais, enriquecendo a sua personalidade, fomentando o seu convívio e compreensão entre todos, levando-o a refletir criticamente sobre a sua própria cultura, no sentido de a valorizar ainda mais (PROGRAMA DE LÍNGUA INGLESA, 2013, p. 5)

Parece-nos fulcral questionar se seria possível valorizar ou respeitar a cultura de outrem quando a sua é desvalorizada e vice-versa.

Atendendo a realidade da representação dos personagens no livro didático em estudo, a tendência é vermos, no processo, alunos a desenvolverem low self-esteem pela própria cultura, porque há pouco desenvolvimento social de seu próprio grupo. Ou seja,

\begin{abstract}
Nesta concepção, esperamos encarar alunos que não produzem conhecimento, pois os temas abordados no livro, com menos ênfase na sua própria cultura, não os interessam porque não têm relação com seu quotidiano, não fazem parte da cultura que permeia as suas relações de interação social (BRITTES; FERREIRA, 2009, p. 8978, grifo nosso).
\end{abstract}

Notemos que se poderia inferir que a arrumação tanto dos textos verbais e nãoverbais e a sub-representação de um grupo em detrimento de outro é deliberada, por outras palavras, em termos de representação, é ideológico. Em relação à falta de uma comunicação entre o discurso verbal e iconográfico, deve-se ao fato de não haver comprometimento com o didatismo em fazer análises críticas capazes de identificar tais problemas e concertá-los. Como já o expressamos, o fator lucro desempenha um papel decisivo, sendo, talvez, um dos principais desígnios para a produção desses materiais. A esse propósito, Barbosa (2013) adverte que o uso de material didático no ensino de línguas tornou-se comum, fomentando lucros vultosos para o mercado editorial, mas nem sempre esses livros são analisados criticamente. Na mesma vertente de pensamento, Tilio (2006, p. 119) diz que:

Um fato importante, no que diz respeito aos livros didáticos de ensino de línguas estrangeiras, é a sua origem. Livros produzidos internacionalmente em países onde o inglês é a língua materna, e visando o mercado global, não conseguem incorporar a realidade sociocultural do aprendente, pois não possuem um público-alvo específico.

Assim, tanto os resultados aqui apresentados quanto o argumento de Barbosa e Tilio confirmam a ideia de Kumaravadivelu (2016), segundo a qual é através de métodos e materiais desenvolvidos pelo Ocidente que a marginalização da maioria é gerida, reforçada e mantida. O autor complementa que estes "elementos são os motores que impulsionam a estrutura do poder hegemônico" (KUMARAVADIVELU, 2016, p. 73). 
Para terminar essa seção, cabe-nos ressaltar que "o papel do ensino, principalmente o de uma língua estrangeira, e principalmente o de inglês, neste momento atual, é o de promover uma maior integração entre a sala de aula, a realidade do aluno e o contexto cultural" (TILIO, 2006, p. 153).

\section{CONSIDERAÇÕES FINAIS}

Os resultados do estudo indicam que, em termos da relação entre a linguagem verbal e a não-verbal, existem evidências de incoerência e incongruência que tornam complexa a compreensão e a interpretação de textos, podendo fragilizar o processo de aprendizagem do aluno. Por sua vez, em termos de representatividade dos grupos em conformidade com os aspetos analisados tais como étnicos, culturais e sociais, notamos assimetrias. O texto exibe um discurso estereotipado, transversal a "muitos livros didáticos, podendo manipular ou subverter realidades, conduzindo professores e aprendizes a um estado de comodismo ou de inferioridade, quando por exemplo exaltam em suas páginas as culturas hegemônicas" (ANJOS, 2017, p. 21).

Sendo de domínio comum que o livro didático tem um papel preponderante na sala de aula no ensino de línguas estrangeiras, seu poder de influenciar negativa ou positivamente no ensino-aprendizagem não deve ser subestimado, visto que "o que o livro apresenta é o que os professores repassam aos alunos, muitas vezes sem convidá-los a ter uma visão crítica" (BRUZ, 2011, p. 6). Portanto, "os livros didáticos tendem a contribuir para propagar os efeitos maléficos [....] disseminando-os e não minimizando-os, como esperado" (SILVA, 2015, p. 2) "por isso, é importante que esse instrumento tente retratar a realidade de uma maneira que convide os alunos e professores a refletirem sobre a língua e sobre a cultura-alvo" (BRUZ, 2011, p. 6).

Perante esta realidade, ficamos com a convicção de que o manual estudado e outros com o mesmo fim educativo devam merecer outras análises e críticas para que sejam ajustados à realidade de vivência dos vários contextos socioculturais, étnicos e econômicos dos alunos, de modo que seus objetivos e sua importância como ferramenta inicial de ensino-aprendizagem na sala de aula tenham reflexos.

Concluímos que é importante salientar que esses contextos servem, sobretudo, de modelo intermediário entre as linguagens verbal e iconográfica facilitando, assim, a transmissão e receção de conhecimento entre o educador (neste caso o manual) e o educando (o aluno), que depende deste material para lhe fornecer as competências necessárias tanto acadêmicas como práticas, úteis para a vida profissional e não só.

\section{REFERÊNCIAS}

AMARAL, E. J. C. O racismo em Angola. NewPaper. N. 4/2018. https://evandroamaral.blogs.sapo.ao/oracismo-em-angola-1032. Acesso em: 8 mar. 2019.

ANJOS, F. A. Ideologia e omissão nos livros didáticos de língua inglesa. Bahia: Ed. UFRB, 2017.

AWAN, F. Young People, Identity and the Media: A Study of Conceptions of Self-identity among Youth in Southern England. Available at http//www.artlab.org.uk/Fatimah-awan-phd.htm, 2008. 
BARBOSA, J.R.A. Multimodalidade e criticidade: Uma análise de textos didáticos para o ensino de Línguas. Rev. de Letras, v. 1, n. 32, p. 62-71, jan./jun. 2013.

BLOCK, D.; GRAY, J. (forthcoming 2017) 'French Language textbooks as ideologically imbued cultural artefacts: Political economy, neoliberalism and (self) branding'. In: COFFEY, S.; WINGATE, U. (Eds.) New Directions for research in Foreign Language Education. Abingdon: Routledge, 2017.

BRITTES, L. R.; FERREIRA, L. S. O "Entrecruzamento Cultural” e as políticas públicas na escola: Uma abordagem sobre o trabalho dos professores numa perspetiva discursiva. In: CONGRESSO NACIONAL DE EDUCAÇÃO - EDUCERE, 9.; ENCONTRO SUL BRASILEIRO DE PSICOPEDAGOGIA, 3., 2629/10/ 2009, Curitiba: PUCPR, 2009.

BRUZ, I. M. Material didático de língua inglesa: Uma análise sobre as relações socio-culturais. Faunter Revista X., v. 2, p. 1-10, 2011.

CARMAGNANI, A.M.A. Concepção de professor e de aluno no livro didático e o ensino de redação em LM e LE. In: CORACINI, M. J. (Org.) Interpretação, autoria e legitimação do livro didático. São Paulo: Pontes, p.127-133, 1999.

CENSO 2014. Resultados Definitivos do Recenseamento Geral da População e da Habitação de Angola. Março, 2016.

DIÁRIO DA REPÚBLICA. DECRETO PRESIDENCIAL nº 105, de 24 de maio de 2011, 2011.

FAIRCLOUGH, N. Discurso e mudança social. Brasília: Universidade de Brasília, 2008.

FAIRCLOUGH, N. Análise Crítica do Discurso como método em pesquisa social científica [Critical Discourse Analysis as a Method in Social Scientific Research]. Linha d'Água, v. 25, n. 2, p. 307-329, 2012.

FARIAS, K. C.; FERREIRA, A. J. Identidades sociais no livro didático de língua inglesa: Representações do discurso escrito de raça/etnia. II SEMINÁRIO NACIONAL EM ESTUDOS DE LINGUAGEM: DIVERSIDADE, ENSINO E LINGUAGEM, 2., 2010, Cascavel, PR. Cascavel: UNIOESTE, 2010. GOVERNO DE ANGOLA. BALANÇO DA IMPLEMENTAÇÃO DA $2^{\mathrm{a}}$ REFORMA EDUCATIVA EM ANGOLA, 2014. Disponível em https://docplayer.com.br/83471846-1-balanco-da-implementacaoda-2a-reforma-educativa-em-angola.html. Acesso em: 2 ago. 2019.

HANRAHAM, M.U. Highlighting hybridity: A critical discourse analysis of teacher talk in the classroom. In: COFFIN, C.; LILLIS, T.M.; O’HALLORAN, K. (Org.). Applied Linguistics Methods: A Reader: Systematic Functional Linguistics, Critical Discourse Analysis and Ethnography. London: Routledge, 2010.

JORNAL DE NEGÓCIOS. PT, 6 jun. 2018.

KUMARAVADIVELU, B. The decolonial option in English teaching: Can the subaltern act?. TESOL Quarterly, v. 50, n. 1, p. 66-85, 2016.

MACHIN, D.; MAYR, A. How to do Discourse Analysis: A Multimodal Introduction. London: SAGE Publications Ltd., 2012.

ORTIZ, M. L. Entrevista com Maria Luiza Ortiz por Denise Scheyerl e Sávio Siqueira. In: SCHEYERL, D.; SIQUEIRA, S. (Org.) Materiais didáticos para o ensino de línguas na contemporaneidade: Contestações e proposições. Salvador: EDUFBA, 2012.

PILATTI, A; SANTOS, M. E. M. O domínio da língua inglesa como fator determinante para o sucesso profissional no mundo globalizado. Revista do Secretariado Executivo, Passo Fundo, v. 4, s.p., 2008.

PROGRAMA DE LÍNGUA INGLESA - $11^{\text {a }}$ Classe Formação de Professores para o Pré-Escolar e para o Ensino Primário. Luanda: Editora Moderna, S.A., 2013.

ROSEMBERG, F.; BAZILLI, C.; SILVA, P. V. B. da. Racismo em livros didáticos brasileiros e seu combate: uma revisão da literatura. Educação e Pesquisa, São Paulo, v. 29, n.1, p.125-146, jan./jun. 2003. ROSEMBERG, F; PIZA, E. Analfabetismo, gênero e raça no Brasil. Revista USP, São Paulo, n. 28, p.110-121, 1996.

SILVA, F.C. Análise da representação do/a negro/a em um livro didático. Revista África e Africanidades, v. 8, n. 20, jul. 2015.

SOUSA, A. B. Multimodalidade: uma Análise Crítica Contrastiva entre os discursos do professor e do aluno. Cadernos do CNLF, v. XIII, n. 4, p. 2128-2140, 2009.

COSTA, Dinis Fernando da. Análise discursiva do livro didático de inglês da 11a classe usado em escolas públicas e privadas de Angola. Linguagem em (Dis)curso - LemD, Tubarão, SC, v. 21, n. 3, p. 311-326, set./dez. 2021. 
TILIO, R.C. O livro didático de inglês em uma abordagem sócio-discursiva: culturas, identidades e pósmodernidade. 2006. Tese (Doutorado em Letras) - Programa de Pós-graduação em Letras, Pontifícia Universidade Católica do Rio de Janeiro, Rio de Janeiro, 2006.

VAN DIJK, A.T. Aims of Critical Discourse Analysis. Japanese Discourse Analysis, v.1, n. 2000, p.1727, 1995.

VAN DIJK, A.T. Ideology and Discourse analysis. Journal of political Ideologies, v. 11, n. 2, p.115-140, 2006.

WODAK, R.; MEYER, M. (2008). Critical Discourse Analysis: History, Agenda, Theory and Methodology. Disponível em: https://us.corwin.com/sites/default/files/upmbinaries/24615_01_Wodak_Ch_01.pdf. Acesso em: 1 jul. 2019.

APÊNDICE

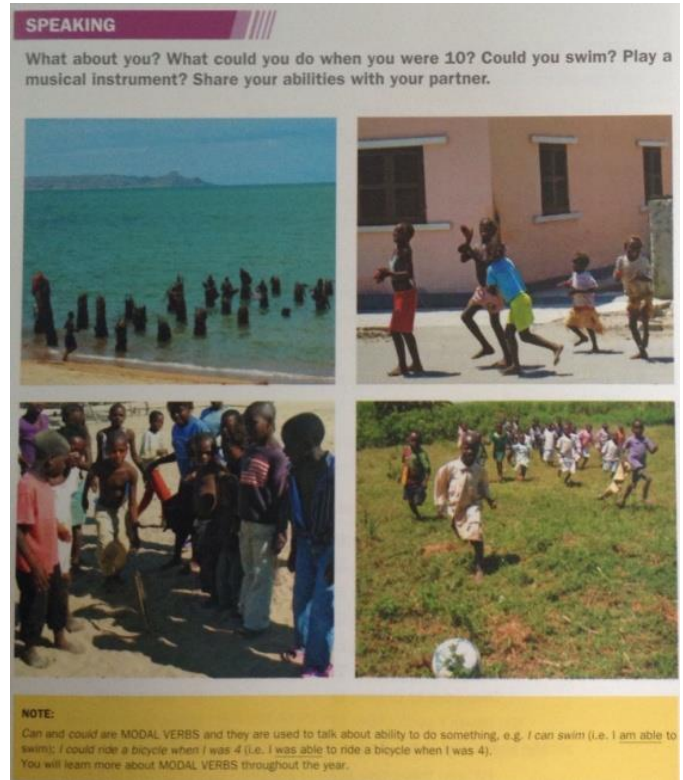

Figura 5 - Childhood activities

Fonte: Manual de Inglês $11^{\text {a }}$ Classe 2014.

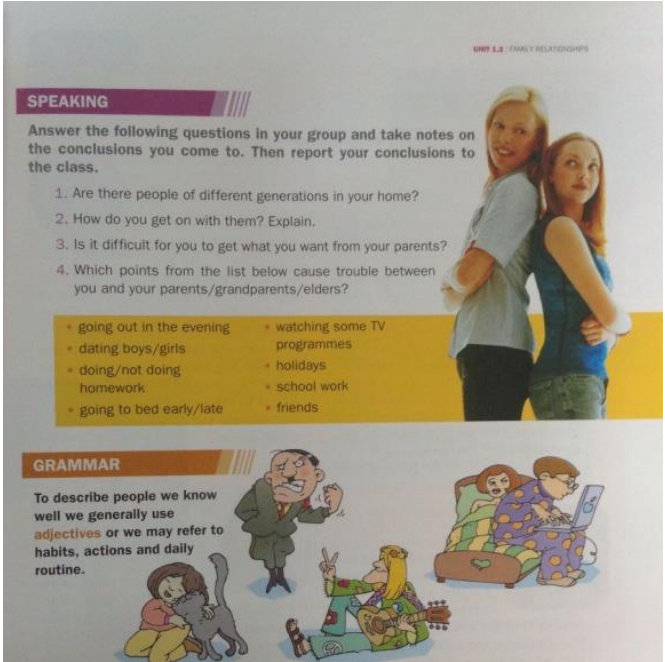

Figura 6 - Family members

Fonte: Manual de Inglês $11^{\text {a }}$ Classe 2014.

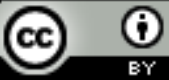

Este texto está licenciado com uma Licença Creative Commons Atribuição 4.0 Internacional.

COSTA, Dinis Fernando da. Análise discursiva do livro didático de inglês da 11a classe usado em escolas públicas e privadas de Angola. Linguagem em (Dis)curso - LemD, Tubarão, SC, v. 21, n. 3, p. 311-326, set./dez. 2021. 